\title{
Evaluation of the eating habits of breast cancer patients
}

\author{
Tuba Kayan Tapan', Zeynep Erdogan lyigun², \\ Serkan Ilgun ${ }^{3}$, Vahit Ozmen ${ }^{4}$
}

\begin{abstract}
Objective: To determine the relationship between the dietary characteristics of breast cancer patients. Methods: Patients with breast cancer whose treatments have finished and are in remission formed the study group and healthy people formed the control group. Demographic, anthropometric characteristics, food consumption frequency form and exercise status were recorded with all groups. Data analysis was done by SPSS 22.

Results: In the study group, mean carbohydrate percentage was lower, while fat, fat percentage, monosaccharide, glucose, fructose, omega3(n3), saturated fatty acids(SFA), monounsaturated fatty acids (MUFA), vitamin A, C, E, B6, biotin and copper values were significantly higher $(p<0.05)$. Recurrence was observed in seven patients (7.1\%) during the follow-up period, hormone receptor levels (ER) and vitamin B2 intake (accuracy 93.9\%) were inversely related to the recurrence of the disease $(p=0.02)$.

Conclusions: While the percentage of carbohydrate taken was lower in study group; total fat, n3, SFA, MUFA, monosaccharide, glucose, fructose, water-soluble fiber, B6, biotin and copper values were higher. Further studies are needed for vitamin B2 deficiency in patients with recurrence.
\end{abstract}

KEYWORDS: Breast Cancer, Nutrition, Recurrence, Diet compliance.

doi: https://doi.org/10.12669/pjms.36.7.2368

How to cite this:

Tapan TK, lyigun ZE, Ilgun S, Ozmen V. Evaluation of the eating habits of breast cancer patients. Pak J Med Sci. 2020;36(7):1562-1566. doi: https://doi.org/10.12669/pjms.36.7.2368

This is an Open Access article distributed under the terms of the Creative Commons Attribution License (http://creativecommons.org/licenses/by/3.0), which permits unrestricted use, distribution, and reproduction in any medium, provided the original work is properly cited.

1. Dr. Tuba Kayan Tapan

Nutrition and Dietetic, Faculty of Health Science,

2. Dr. Zeynep Erdogan lyigun

Physical therapy and rehabilitation,

Faculty of Health Science,

3. Dr. Serkan Ilgun

General Surgery Faculty of Medicine,

4. Dr. Vahit Ozmen

General Surgery Faculty of Medicine

Istanbul University, Istanbul, Turkey.

1-3: Demiroglu Bilim University,

Istanbul, Turkey.

Correspondence:

Dr. Tuba Kayan Tapan

Dietitian, Assistant Professor,

Faculty of Health Science,

Head of Nutrition and Dietetics Department,

Demiroglu Bilim University, Istanbul, Turkey.

E-mail: kyn.tuba@gmail.com

* Received for Publication:

* $1^{\text {st }}$ Revision Received:

* $2^{\text {nd }}$ Revision Received:

* Final Revision Accepted:
February 13, 2020

March 28, 2020

September 4, 2020

September 8, 2020

\section{INTRODUCTION}

Breast cancer is the most common cancer and the cause of death in women. ${ }^{1}$ In recent years, there has been a significant increase in diseasefree and overall survival with early diagnosis and modern treatments. ${ }^{2}$ This increase naturally requires protection from other diseases and their complications for a healthier life. ${ }^{3}$ The relationship between obesity and sarcopenia and mortality was found in patients receiving breast cancer treatment. Therefore, nutrition during the treatment and follow-up period gains importance both in terms of preventing sarcopenia and weight control. Patients are required to meet $45-65 \%$ of their daily energy from carbohydrate, $20-35 \%$ from fat and $10-35 \%$ from proteins during and after chemotherapy. These rates can be achieved by consuming five portions of vegetables and fruits, 
120-150 grams of meat and two cups $(200 \mathrm{ml})$ of milk and milk products per day. In a study of Brown et al., it has been shown that regular consumption of vegetables and fruits and exercise programs together increase survival rates. However, there are also studies showing that consumption of vegetables and fruits has no effect on survival. ${ }^{4,5}$ Although there is different information about the effect of diet on survival in patients diagnosed with breast cancer, it is known that healthy and balanced diet has a positive effect on the quality of life and general well-being of individuals.

It has been observed that the diet content of breast cancer patients decreases and changes during their treatment. This is due to factors such as the prevalence of the disease, associated digestive system disorders, increasing nutritional requirements and incorrect diet practices by patients or health professionals. ${ }^{6}$ This study aimed to investigate the relationship between dietary characteristics and tumor characteristics of breast cancer patients and investigate the compliance of patients with dietary recommendations.

\section{METHODS}

In November 2019-January 2020, at the Istanbul Florence Nightingale Hospital Breast Health Center, and people without randomly selected. The study group consisted of 98 patients who completed breast cancer treatment and followed in remission and the control group, was 89 volunteer women with similar demographic characteristics with no cancer history. Cross sectional study was designed. Both were 18 years old and above. There are limitations of being diagnosed with breast cancer in the study group, and not having breast cancer diagnosis in the control group, and not using psychiatric drugs. All participants were interviewed face-toface, recording the demographic characteristics (gender, age, marital-educational status), body mass index (BMI). The frequency of nutrient consumption form ${ }^{7}$ was filled by themselves in to determine the average daily energy and nutrient consumption amounts in diet and physical activity status was evaluated $(\geq 100 \mathrm{~min} / \mathrm{w}$ were considered to exercise regularly). Before the study, patients were informed about portion control training. Height and weight measurements were carried out with Seca ${ }^{\circledR}$ (Medizinische Messsysteme und Waagen/Hamburg Deutschland.) electronic weighing system. BMI was classified with World Health Organization classification $(\leq 19.9$; $=20-29.9$; and $\geq 30) .{ }^{8}$ The data obtained from the nutrient consumption frequency form was evaluated with the full version of Nutrition Information Systems 7.2. The calculated nutrient values were calculated with the Dietary Reference Intake (DRI) system adapted to gender and age. ${ }^{9}$ Patients who meet $67 \%$ of the references were classified inadequate, $67 \%-133 \%$ were sufficient and $\geq 133 \%$ were overconsumption. ${ }^{10}$ Istanbul Bilgi University Ethics Committee; 2019-40016-148 with Number and the date is five November 2019.

Statistical Methods: SPSS 22 (IBM) software was used for statistical analysis. Distribution analysis of data was Kolmogorov-Smirnov, non-parametric independent data was the Mann-Whitney U, parametric data was Student T-test, dependent data was Wilcoxon test performed with. In the analyses, $\mathrm{p}<0.05$ was accepted as significant.

\section{RESULTS}

When the groups were compared in terms of age and BMI, comorbid diseases (diabetes, hyperlipidemia, coronary heart disease and hypertension) and smoking, no significant difference was found between the groups. The study group was found to do more exercise (Table-I).

When the patients were divided into four groups according to their BMI $(\leq 19.9 ;=20-24,99,=25-29,99$ and $\geq 30)$, the groups were similar $(\mathrm{P}=0.693)$. Three of the patients received neoadjuvant and 96 of them received adjuvant chemotherapy. The mean weights at the end of the follow-up period of 45 months ( $\pm 31,7$ months) and the weights measured at the time of diagnosis were found to be the same $(69 \pm 13 \mathrm{~kg}$ vs $68.3 \pm 12.59 \mathrm{~kg}, \mathrm{p}=0.352)$. The amounts are different, but $\mathrm{p}$ ratio is not different. (Table-I).

Table-I: Demographic characteristics of the study and control group.

\begin{tabular}{lccc}
\hline Demographic Characteristics & Study Group $(n=99)$ & Control Group $(n=89)$ & $p$ \\
\hline Age (median(min-max)) & $47.5(24-79)$ & $46(23-79)$ & $0.074^{\mathrm{a}}$ \\
BMI(median(min-max)) & $26.5(17.7-43)$ & $27.1(17.5-31.1)$ & $0.87^{\mathrm{a}}$ \\
Internal disease $(\mathrm{n}(\%))$ & $32(32.3)$ & $35(39.3)$ & $0.34^{\mathrm{b}}$ \\
Exercise habit $(\mathrm{n}(\%))$ & $59(59.5)$ & $24(26.9)$ & $0.00^{\mathrm{b}}$ \\
Smoking $(\mathrm{n}(\%))$ & $6(6)$ & $9(10.1)$ & $0.49^{\mathrm{b}}$ \\
\hline
\end{tabular}

astudent T-test, bchi-square test. 
In the comparison of the average consumption amounts of both groups with the daily requirements; carbohydrates were taken less than the amount required in all. However, the daily amount of energy required to be taken from fats as well as vitamins $\mathrm{A}, \mathrm{E}, \mathrm{B}_{2}, \mathrm{~B}_{12}, \mathrm{E}$ and $\mathrm{C}$, magnesium, zinc, and niacin were taken more than required. In the study group, the percentage of energy coming from fat and vitamins $\mathrm{A}, \mathrm{E}, \mathrm{B}_{2}, \mathrm{~B}_{6}, \mathrm{C}, \mathrm{B}_{12}$ were taken more than the daily required amount according to the DRI recommendations. In the control group, the percentage of energy coming from fat and vitamins $A, B_{1}, B_{2}, B_{6}, C, B_{12}$ were taken in excess according to DRI recommendations. However, when the groups were compared, the daily intake of total fat, $n_{3^{\prime}}$ SFA and MUFA were higher in the study than the control group (Table-II).

Total 58 patients $(58.6 \%)$ stated that they changed their dietary habits after the diagnosis of breast cancer. However, no significant difference was found in consumed amounts between the groups that changed and did not change the dietary habits $(\mathrm{p}>0.05)$.

When the use of dietary supplements of the groups were examined, $45(45.9 \%)$ individuals in the study and $37(41.5 \%)$ in the control group were using dietary supplements. Vitamin D, turmeric, ginger, and propolis were used. There was no difference between the groups in terms of usage $(p=0.55)$. No significant difference was between
BMI and tumor size, ER, $\mathrm{Ki}_{67}$, molecular subtypes of the tumor and nutrient consumption rates.

In the study group (median 45 months (14-96) follow-up), local or systemic recurrences were observed in seven individuals. No significant difference was found in the treatments, disease stages, progesterone receptor, $\mathrm{Ki}_{67}$, ER ratios, BMI, age and exercise habits between patients with and without recurrence $(p<0.05)$. Between with and without recurrence, a significant difference was found in the amount and percentage of daily protein, water amount, vitamin $\mathrm{A}$, galactose, $\mathrm{n}_{3}$, biotin, $\mathrm{B}_{1}, \mathrm{~B}_{2}$ and niacin intake. In the logistic regression model, where these different parameters and the ER ratio which is also different between the two groups were included, vitamin $B_{2}$ was determined as independent variables $(p=0.02)$. In the multivariate reduced model (accuracy 93.9\%), the ER rate and the vitamin $\mathrm{B}_{2}$ taken in the diet were inversely correlated with the systemic or local recurrence of the disease $(\mathrm{OR}=0,19$ is low effective, $\mathrm{OR}=0,97$ is high effective) (Table-III).

\section{DISCUSSION}

Studies have shown that high BMI is among the risk factors for breast cancer. ${ }^{11}$ Therefore, weight control is recommended to patients after diagnosis and patients with this recommendation vary. In the literature, compliance with the weight control recommendation of patients after breast cancer is

Table-II: Comparison of daily nutrient consumption between study and control groups.

\begin{tabular}{|c|c|c|c|c|c|c|c|}
\hline Energy and Nutrients & $\begin{array}{l}\text { Study Group } \\
\bar{x}\end{array}$ & $\begin{array}{l}\text { Control Group } \\
\bar{x}\end{array}$ & $p$ & $\begin{array}{l}\text { Energy and } \\
\text { Nutrients }\end{array}$ & $\begin{array}{c}\text { Study Group } \\
\bar{x}\end{array}$ & $\begin{array}{c}\text { Control Group } \\
\bar{x}\end{array}$ & $p$ \\
\hline Energy(kcal) & 2221.066 & 2066.219 & 0.226 & Vitamin $B_{1}(m g)$ & 1.26 & 3.837 & 0.311 \\
\hline Carbohydrate(g) & 193.631 & 209.019 & 0.14 & Vitamin $B_{2}(m g)$ & 1.802 & 1.78 & 0.895 \\
\hline Carbohydrate $(\%)$ & 35.96 & 41.247 & 0 & Vitamin $\mathrm{B}_{6}(\mathrm{mg})$ & 1.928 & 1.76 & 0.034 \\
\hline Protein $(\mathrm{g})$ & 90.575 & 88.404 & 0.689 & Vitamin $B_{12}(\mathrm{mg})$ & 7.93 & 6.526 & 0.554 \\
\hline Protein $(\%)$ & 16.848 & 17.382 & 0.07 & Niacin(mg) & 29.045 & 30.624 & 0.265 \\
\hline Fat $(\mathrm{g})$ & 117.982 & 94.887 & 0.002 & Biotin(mg) & 65.011 & 56.199 & 0.01 \\
\hline Fat $(\%)$ & 46.758 & 41.213 & 0 & Vitamin $C(g)$ & 199.213 & 159.866 & 0.042 \\
\hline Cholesterol(mg) & 347.66 & 346.031 & 0.925 & Vitamin $\mathrm{D}(\mathrm{mg})$ & 1.612 & 1.56 & 0.919 \\
\hline SFA(g) & 36.139 & 31.004 & 0.056 & Vitamin E(mg) & 22.66 & 18.142 & 0.049 \\
\hline MUFA(gr) & 49.922 & 36.517 & 0 & Cupper(mg) & 2.536 & 2.115 & 0.002 \\
\hline PUFA(g) & 24.583 & 20.213 & 0.135 & Calcium(mg) & 954.745 & 1050.774 & 0.083 \\
\hline $\mathrm{Omega}_{3}(\mathrm{~g})$ & 2.813 & 2.294 & 0.007 & Magnesium(mg) & 450.789 & 429.299 & 0.471 \\
\hline $\mathrm{Omega}_{6}(\mathrm{~g})$ & 21.767 & 18.128 & 0.12 & Potassium(mg) & 3561.999 & 3355.741 & 0.171 \\
\hline Monosaccharides(g) & 40.849 & 26.766 & 0 & Selenium(mg) & 0.082 & 0 & 0.338 \\
\hline Galactose(g) & 1.859 & 3.036 & 0.683 & Sodium(mg) & 2615.534 & 2448.144 & 0.945 \\
\hline Fructose(g) & 19.929 & 14.568 & 0.002 & Zinc(mg) & 12.961 & 13.02 & 0.867 \\
\hline Glucose (g) & 17.958 & 14.107 & 0.005 & Fiber $(\mathrm{g})$ & 33.304 & 32.236 & 0.28 \\
\hline Vitamin A(mg) & 1858.936 & 1494.68 & 0.05 & Water soluble fiber $(\mathrm{g})$ & 11.215 & 10.136 & 0.049 \\
\hline Carotene(mg) & 3.055 & 3.354 & 0.492 & Water(ml) & 1461.787 & 1387.821 & 0.362 \\
\hline
\end{tabular}

${ }^{*} \mathrm{p}<0.05$. 
Tuba Kayan Tapan et al.

Table-III: The effect of diet on disease recurrence.

\begin{tabular}{lcccccccc}
\hline & \multicolumn{3}{c}{ Univariate Model } & \multicolumn{5}{c}{ Multivariate Reduced Model } \\
\cline { 2 - 8 } & OR & \multicolumn{2}{c}{ 95\% confidence interval } & $p$ & OR & 95\% confidence interval & $p$ \\
\hline ER rate & 0.97 & 0.95 & 0.99 & 0.02 & 0.97 & 0.96 & 0.99 & 0.02 \\
Water(ml) & 0.99 & 0.99 & 1 & 0.03 & & & & \\
Protein(g) & 0.97 & 0.94 & 0.99 & 0.02 & & & \\
Protein(\%) & 0.79 & 0.57 & 0.97 & 0.031 & & & \\
Biotin(mg) & 0.96 & 0.92 & 0.99 & 0.038 & & & \\
Vitamin A(mg) & 0.99 & 0.99 & 1 & 0.031 & & & \\
Vitamin $B_{1}(\mathrm{mg})$ & 0.12 & 0.01 & 0.81 & 0.03 & & & \\
Vitamin $\mathrm{B}_{2}(\mathrm{mg})$ & 0.17 & 0.04 & 0.66 & 0.01 & 0.19 & 0.46 & & \\
Galactose(g) & 0.38 & 0.15 & 0.97 & 0.04 & & & & \\
Omega $(\mathrm{g})$ & 0.36 & 0.14 & 0.9 & 0.02 & & & & \\
Niacin(mg) & 0.9 & 0.86 & 0.99 & 0.04 & & & & \\
\hline
\end{tabular}

OR: odds ratio, ER: estrogen receptor ratio.

reported as $58-77 \% .{ }^{12}$ In this study, when the mean BMI of patients was taken, no significant difference was found between pre and post-diagnostic.

Poor dietary habit characterized with highly refined sugar and both saturated and trans fat consumption, low $\mathrm{n}_{3}$, natural antioxidants, and fiber intake, appears to be linked to increased risk of breast cancer and death by modulating inflammation. On average, obesity increases the mortality risk by approximately $30 \%$. In another study, it was reported that obesity increased the risk of breast cancer by $35-40 \% .{ }^{13}$ The fact that women often gain weight after the diagnosis of breast cancer also increases the risk of death and survival. Not only dietary habits but also body weight control should be given more importance. ${ }^{14}$

There is a desire to change lifestyles and dietary habits in patients diagnosed with cancer. In this study, $58.6 \%$ of the patients changed their diet after diagnosis with the recommendation of a doctor or dietician. In Malaysian, $57.8 \%$ of the patients reported that they changed their diet at a similar rate to our study. ${ }^{15}$ In a meta-analysis, dietary change after diagnosis was to reduce energy intake, increase vegetable and fruit consumption, to increase fiber intake and improve dietary quality. However, in our study, these changes didn't make any difference in weight and BMI. After the diagnosis of breast cancer, the use of food supplements is also increasing. In a study, the use of nutritional supplements was $56 \%$ before, $62 \%$ after diagnosis. The most commonly used supplements were found to be fish oil, multivitamins and minerals and evening primrose oil. ${ }^{16}$ In our study, taken food supplements did not increase significantly after the diagnosis compared to the control group $(p>0.05)$. Taken food supplements are identified as $\mathrm{n}_{3}$, vitamin $\mathrm{D}$, green tea and ginger.

In this study, the ratio of energy from carbohydrates was found to be $36 \%$. Although a low carbohydrate diet or a ketogenic diet is recommended in breast cancer patients, evidence supporting the effect of these diets on survival is insufficient. ${ }^{17}$ It was determined that breast cancer patients had a higher rate of fat intake and fat percentage $(46.7 \%)$ was higher than carbohydrates $(35,9 \%)$. However, studies showing that although weight loss is observed in individuals fed with a low-fat diet, it does not affect survival in breast cancer..$^{18}$ In a study, 48,835 postmenopausal women, it was proved that a low-fat diet reduces the risk of dying from breast cancer for a postmenopausal woman. ${ }^{19}$

Among women, $n_{3}$, PUFA intake was found to be inversely related to breast cancer risk and mortality.$^{20}$ In our study, the average daily intake of $\mathrm{n}_{3}(2.8 \mathrm{~g} /$ day $)$ increased due to the excess amount of fish, green leafy vegetables, and oilseeds consumed weekly. The amount of MUFA(49.92\%) was high, due to the high amount of olive oil taken on a daily diet. The total fat intake is high, because the high consumption of natural butter and fish. Breast cancer risk is positively correlated with SFA, $\mathrm{n}_{3} /$ $\mathrm{n}_{6} \cdot \mathrm{N}_{3}$-rich diet, increased fish and reduced $\mathrm{n}_{6}$ consumption reduce the risk of breast cancer. ${ }^{21}$ It is stated that $n_{3} / n_{6}$ ratio of diets rich in vegetables and fruits (Mediterranean diet), physical activity, and low BMI are effective in preventing breast cancer. ${ }^{22}$

High plasma vitamin $B_{6}$ and $B_{2}$ can reduce the risk of breast cancer especially in premenopausal women and also has a protective effect against breast cancer. ${ }^{23} \mathrm{ER}$ rate and the amount of vitamin $B_{2}$ taken in the diet were found to be inversely 
correlated with the systemic or local recurrence of the disease, in this study $(\mathrm{p}=0.02)$.

Limitations of the study: The number of studies about the dietary habits of breast cancer patients in Turkey is limited. There is no similar study. The compliance of the treated breast cancer patients to oncologist and dietician recommendations resulted in less consumption of carbohydrate (bread), but more frequent consumption of whole wheat flour, rye, oat bread, leading to higher vitamin $\mathrm{B}_{6}$ intake. High frequency of fish, nuts, and olive oil, natural butter consumption increase the amount and percentage of fat. In our study, when study group, with and without recurrence are compared; the ER rate and the vitamin $B_{2}$ were found to be different between two groups (study group >control group) and identified as independent variables.

\section{CONCLUSION}

BMI values remained the same in patients receiving breast cancer treatment, although they adhered to a healthy diet and regular exercise recommendations. According to our study, increasing the ratio of vitamin $B_{2}$ in the diet may contribute to the prevention of recurrences, but more patients and more comprehensive prospective clinical studies are needed in this front.

\section{Grant Support E Financial Disclosures: None. \\ REFERENCES}

1. Bray F, Ferlay J, Soerjomataram I, Siegel RL Torre LA, Jemal A. Global cancer statistics 2018: GLOBOCAN estimates of incidence and mortality worldwide for 36 cancers in 185 countries. CA Cancer J Clin. 2018;68(6):394-424. doi: 10.3322/caac.21492

2. Kocak S, Celik L, Ozbas S, Dizbay S, Sak SD, Tukun A, et al. Meme Kanserinde Risk Faktörleri, Riskin Degerlendirilmesi Ve Prevansiyon: Istanbul 2010 Konsensus Raporu. J Breast Health. 2011;7(2):47-67. In Turkish

3. DeSantis CE, Ma J, Goding Sauer A, Newman LA, Jemal A. Breast cancer statistics, 2017, racial disparity in mortality by state. CA Cancer J Clin. 2017;67(6):439-448. doi: 10.3322/ caac. 21412

4. Brown JK, Byers T, Doyle C. Nutrition and physical activity during and after cancer treatment: An American Cancer Society guide for informed choices. CA Cancer J Clin. 2003;53:268-291. doi: $10.3322 /$ canjclin.53.5.268

5. De Cicco P, Catani MV, Gasperi V, Sibilano M, Quaglietta M, Savini I. Nutrition and Breast Cancer: A Literature Review on Prevention, Treatment and Recurrence. Nutrients. 2019;11(7):pii: E1514. doi: 10.3390/nu11071514

6. Gunes FE, Imeryuz N, Akalin A, Bekiroglu N, Alphan E, Oguz $\mathrm{A}$, et al. Development and validation of a semi-quantitative food frequency questionnaire to assess dietary intake in Turkish adults. DJ Pak Med Assoc. 2015;65(7):756-763.

7. Demark-Wahnefried W, Campbell KL, Hayes SC. Weight management and its role in breast cancer rehabilitation. Cancer 2012;118(8):2277-2287. doi: 10.1002/cncr.27466

8. Classification of malnutrition in adults by body mass index. (http://apps.who.int/bmi/index.jsp?introPage=intro_3.html) Accessed on 26/06/2018.
9. Dietary Reference Intakes. (http://ods.od.nih.gov/Health Information/Dietary_Reference_Intakes.aspx) Accessed on $26 / 06 / 2018$

10. Pekcan G. Beslenme Durumunun Saptanması. Diyet El Kitab1 (Baysal A, ed). 7. Baskı. Ankara, Hatipoglu. 67-142, 2013. In Turkish

11. Suzuki Y, Tsunoda H, Kimura T, Yamauchi H. BMI change and abdominal circumference are risk factors for breast cancer, even in Asian women. Breast Cancer Res Treat. 2017;166(3):919-925. doi: 10.1007/s10549-017-4481-4

12. Seiler A, Chen MA, Brown RL, Fagundes CP. Obesity, Dietary Factors, Nutrition, and Breast Cancer Risk. Curr Breast Cancer Rep. 2018;10(1):14-27. doi:10.1007/s12609-018-0264-0

13. Vance V, Mourtzakis M, McCargar L, Hanning R: Weight gain in breast cancer survivors: prevalence, pattern and health consequences. Obes Rev. 2011;12:282-294. doi: 10.1111/j.1467789X.2010.00805.x

14. Shaharudin SH, Sulaiman S, Shahril MR, Emran NA, Akmal SN. Dietary changes among breast cancer patients in Malaysia. Cancer Nurs. 2013;36(2):131-138. doi: 10.1097/ NCC.0b013e31824062d1

15. Weigl J, Hauner H, Hauner D. Can Nutrition Lower the Risk of Recurrence in Breast Cancer? Breast Care (Basel). 2018;13(2):8691. doi: $10.1159 / 000488718$

16. Chlebowski RT, Aragaki AK, Anderson GL, Simon MS, Manson JE, Neuhouser ML, et al. Association of Low-Fat Dietary Pattern With Breast Cancer Overall Survival A Secondary Analysis of the Women's Health Initiative Randomized Clinical Trial. JAMA Oncol. 2018;4(10):e181212. doi: 10.1001/jamaoncol.2018.1212

17. Chlebowski RT, Aragaki AK, Anderson GL, Pan K, Neuhouser $\mathrm{ML}$, Manson JE, et al. Low-fat dietary pattern and long-term breast cancer incidence and mortality: The Women's Health Initiative randomized clinical trial. J Clin Oncol. 2019:520-520. doi: 10.1200/JCO.2019.37.15_suppl.520

18. Seiler A, Chen MA, Brown RL, Fagundes CP. Obesity, Dietary Factors, Nutrition, and Breast Cancer Risk. Curr Breast Cancer Rep. 2018;10(1):14-27. doi: 10.1007/s12609-018-0264-0

19. Bassett JK, Hodge AM, English DR, MacInnis RJ, Giles GG. Plasma phospholipids fatty acids, dietary fatty acids, and breast cancer risk. Cancer Causes Control. 2016;27(6):759-773. doi: 10.1007/s10552-016-0753-2

20. Lahart IM, Metsios GS, Nevill AM, Carmichael AR. Physical activity, risk of death and recurrence in breast cancer survivors: A systematic review and meta-analysis of epidemiological studies. Acta Oncol. 2015;54(5):635-654. doi: 10.3109/0284186X.2014.998275

21. Ansa B, Yoo W, Whitehead M, Coughlin S, Smith S. Beliefs and behaviors about breast cancer recurrence risk reduction among African American breast cancer survivors. Int J Environ Res Public Health. 2015;13(1):46. doi: 10.3390/ijerph13010046

22. Shapira N. The potential contribution of dietary factors to breast cancer prevention. Eur J Cancer Prev. 2017;26(5):385-395. doi: 10.1097/CEJ.0000000000000406

23. Agnoli C, Grioni S, Krogh V, Pala V, Allione A, Matullo G, et al. Plasma Riboflavin and Vitamin B-6, but Not Homocysteine, Folate, or Vitamin B-12, Are Inversely Associated with Breast Cancer Risk in the European Prospective Investigation into Cancer and Nutrition. J Nutr. 2016;146(6):1227-1234. doi: $10.3945 /$ jn.115.225433

Authors' Contribution: TKT: Conceived, designed, data collection, editing of the manuscript and takes the responsibility and is accountable for all aspects of the work in ensuring that questions related to the accuracy or integrity of any part of the work are appropriately investigated and resolved. ZEI, SI: Conceived, designed and did statistical analysis \& editing of manuscript. VO: Critical Review and final approval of manuscript. 